Journal of Economics and Behavioral Studies

Vol. 3, No. 6, pp. 360-362, Dec 2011 (ISSN: 2220-6140)

\title{
Distance Matters: Evidence from the Game of Cricket
}

\author{
*Muhammad Imtiaz Subhani, Syed Akif Hasan, Amber Osman, Bilal Hussain, Ahmed Ali, Faizan Farid, Osama \\ Faheem \\ Iqra University Research Centre, Iqra University, Karachi, Pakistan \\ *drsubhani@yahoo.co.uk
}

\begin{abstract}
Playing at home ground gives advantage to the home side always, though the strength of the teams also plays a major role in the eventual outcome of a given match. It is observed that India is remarkable when it plays at home; however, it becomes quite an ordinary side when it plays at opponents' home ground. Meanwhile, Australia, which has been the most consistent team for several decades played well both at home and away. After studying the 50-years data of home and away matches for all major cricket playing teams via split technique, it was found that the teams won their matches more, when they play at their home grounds, while playing at opponent's home-ground may snatch away the victory from them.
\end{abstract}

Keywords: Home Grounds, Home Crowd, Home Away, Cricket

\section{Introduction}

The purpose of the study is to confirm the importance of distance in the game of cricket while investigating the difference in eventual results when a team plays at home and when it plays at the home-ground of the opponents, precisely this paper investigates whether or not distance matters in the game of cricket when the teams play at the opponent home grounds. Former legendary player Abbas (2010) said and commented that the home-team has the privilege to decide how to prepare a pitch for a certain match, for instance, if Pakistan plays against India in India, then the Indians would prepare a pitch, which favors batsmen, as Pakistan's strength is bowling and its batsmen are quite ordinary. However, they could make a different kind of pitch when it plays against Australia as they are skilled in both batting and bowling department.

Meanwhile, Qasim (2006) a former Pakistan cricket spin bowler, said that the crowd's support to the home team and aggression towards the visitors, boosts the morale of the home teams while demoralize the visiting ones, which gives a huge advantage to the hosts. However, legendary former skipper and director general Pakistan Cricket Board (PCB) Miandad (2010) believes that great players performance is never affected by the climate and crowd factor. Miandad further stressed that he loved when he used to play at opponents home ground, where the crowd was aggressive and he found such aggression for him a motivating factor to play and perform well. Smith et al. (2002) confirmed that Pakistani team is found to have more aggression while playing against India when the playing venue is not home ground and this enables Pakistani team to play smarter cricket and win matches. In contrast Pollard (1986) is convinced that it is home venues, which actually give the rigorous advantage in shape of audience support etc. to the home teams and fruits the wins.

The home advantage remains one of the least understood phenomena in sports (Bruce \& Dennis, 2005). The 53 percent to 70 percent results always go in favour of the teams hosting the matches (Courneya \& Carron, 1992).The purpose of this paper is to provide an empirical framework to reach to a conclusion on the importance of distance in the game of cricket, and How far the distance translates the outcomes of cricket matches from the data of test matches and one dayers from 1961 to the World Cup 2011 for all major cricket playing nations?

\section{Literature Review}

The home advantage in sports always refers to the consistency with which host / home teams win near to $50 \%$ of the games contested even before the game starts (Courneya \& Carron, 1992). Pollard (1986); Bruce \& 
Dennis (2005) confirmed that it's the ground not the players which decides the outcome of the games in most of the cases. Courneya and Carron also found out that the home advantage has been shown to be perpetual and stable within sports, consistent over time, consistent at different levels of competition. Courneya and Carron then convincingly concluded that 53 percent to 70 percent results always go in favor of the teams hosting the matches. They also reported that the familiarity with the home ground and the home crowd are the important factors, which influence the team performance and hence affect the outcomes of the games.

Schwartz and Barsky (1977) suggested that the amount, magnitude and the intensity of a home advantage vary in accordance with the strength and quality of the home teams and their visiting opponents. In short, a superior home team would win a huskier percentage of games against inferior visiting teams, while it is slim against equally matched visitors. Schwartz and Barsky reported found that home advantage is rooted in the social support, which fans give to the home teams. The social support of the home team is a celebration of the local community in presence of the representatives of alien communities.

Smith, Ciacciarelli, Serzan, and Lambert (2002) have found that the home team consistently wins over 50\% of sporting contests. Playing on a team's home court was as important a determinant of game outcome as is the quality of the teams in the contest (Smith et al., 2002). Neville, Balmer, and Williams (2002) have also established the existence of the home advantage in all types of sports. Neville, Balmer, and William investigated and found the growing evidence that crowd noise plays a crucial part in winning and losing any game. They then concluded that the noise of the crowd influences referees' decisions to favor the home team. Pollard (1986) also found that the existence of home advantage has been established as a key driving force for paving the ways towards the wins for all major professional sports.

\section{Methodology}

To answer the question that how far the distance translates the outcomes of cricket matches the data of test matches and one dayers from 1961 to the World Cup 2011 for all major cricket playing nations which include Australia, Bangladesh, England, India, New Zealand, Pakistan, South Africa, Sri Lanka, West Indies and Zimbabwe are taken to draw the results. The split technique to enumerate the average scores (percentage) was used to analyze the data.

\section{Results}

The primary focus of this paper is to confirm the effect of distance on matches' outcome. Table 1 reveals that for all outlined playing nations, average percentage scores of winning matches are found better when the matches are played at Home by the stated nations, while for most of the outlined playing nation's percentage scores of loosing matches are observed more when the matches are played at away than those at home. Results also revealed that approximately 60 percent wins are conferred when playing venues are home. The revealed findings logically reflects that playing at home ground is same as you are at home with your family which sooths to your psychic and creates a comfort zone to act freely thus it enables team and its players to play with comfort and perform better.

Table 1: Average scores ( in Percentage )

\begin{tabular}{lllll}
\hline TEAMS & DISTANCE & WINS & LOSSES & DRAWS \\
\hline AUSTRALIA & HOME & $73 \%$ & $10 \%$ & $17 \%$ \\
\multirow{2}{*}{ BANGLADESH } & AWAY & $59 \%$ & $20 \%$ & $21 \%$ \\
& HOME & $11 \%$ & $81 \%$ & $8 \%$ \\
ENGLAND & AWAY & $5 \%$ & $85 \%$ & $10 \%$ \\
\multirow{2}{*}{ INDIA } & HOME & $51 \%$ & $27 \%$ & $22 \%$ \\
\multirow{2}{*}{ NEWZEALAND } & AWAY & $33 \%$ & $31 \%$ & $36 \%$ \\
& HOME & $62 \%$ & $22 \%$ & $18 \%$ \\
& HWAY & $30 \%$ & $51 \%$ & $29 \%$ \\
& HOME & $42 \%$ & $30 \%$ & $28 \%$ \\
& AWAY & $37 \%$ & $39 \%$ & $24 \%$
\end{tabular}




\begin{tabular}{|c|c|c|c|c|}
\hline \multirow[t]{2}{*}{ PAKISTAN } & HOME & $61 \%$ & $27 \%$ & $12 \%$ \\
\hline & AWAY & $49 \%$ & $41 \%$ & $10 \%$ \\
\hline \multirow[t]{2}{*}{ SOUTH AFRICA } & HOME & $71 \%$ & $14 \%$ & $15 \%$ \\
\hline & AWAY & $46 \%$ & $35 \%$ & $19 \%$ \\
\hline \multirow[t]{2}{*}{ SRILANKA } & HOME & $41 \%$ & $47 \%$ & $12 \%$ \\
\hline & AWAY & $39 \%$ & $44 \%$ & $17 \%$ \\
\hline \multirow[t]{2}{*}{ WEST INDIES } & HOME & $66 \%$ & $21 \%$ & $13 \%$ \\
\hline & AWAY & $46 \%$ & $30 \%$ & $24 \%$ \\
\hline \multirow{2}{*}{ ZIMBABWAE } & HOME & $20 \%$ & $67 \%$ & $13 \%$ \\
\hline & AWAY & $13 \%$ & $71 \%$ & $16 \%$ \\
\hline
\end{tabular}

\section{Discussions and Conclusion}

It has been confirmed in this paper that distance plays a key and pivot role in translating the matches' outcomes in the game of cricket. The findings depict that for all outlined playing nation-winning scores are greatly injured and got slimmed when the venues of the matches are not home grounds for them. Sports teams enjoy a big and husky advantage whenever they play at home. Home teams have the crowd behind them, filling them with confidence, while, their opponents (visiting teams) have to deal with the crowd's open hostility which drains confidence away which in turn translates the bad result for most of the times. Smith, Ciacciarelli, Serzan, and Lambert (2002) are agreed with the idea that dealing with the hostility of the audience and crowed around you is not an easy job thus it harms the performance of an individuals and hence the teams.

Neville, Balmer, and Williams (2002) confirmed the existence of the home advantage and the disadvantage when not being at home in all types of sports. Though the strength of a team matters a lot in giving outcomes of the matches in the game of cricket as one can see for the Australia that it has a most fascinating winning record at the venues which include Home and Away both but the distance not rarely but most often has its overwhelming impact on the outcomes of the matches. Precisely, the players feel more comfortable in the home ground when they are in front of the local crowd. Familiarity with the home court and home crowd support are perceived to have the greatest influence on team performance.

\section{References}

Abbas, Z. (2010). I was born in the wrong era. Retrieved July 24, 2011 from http://www.jang.com.pk/thenews/oct2010-weekly/nos-07-11-2010/spo.htm.

Bruce, M. \& Dennis, T. (2005). An Investigation of Home Advantage and other factors affecting outcomes in English One Day Cricket Matches. Journal of Sports Sciences, 23(3), 261-268.

Courneya, K. \& Carron, A. V. (1992). The Home Advantage in Sports competition. Journal of Sport \& Exercise Psychology (JESP), 14 (I),13-27.

Schwartz, B. \& Barsky, S. F. (1977). The Home Advantage. Social Forces, 55, 641-661.

Smith, D. R., Ciacciarelli, Serzan \& Lambert. C. (2002). The Home Advantage Revisited: Winning and Crowd Support in an era of National Publics. Sociology of Sports Journal (SSJ), 17(4), 364-385.

Miandad, J. (2010). Ships of Fools, Cricket: The ins, outs, and overs. Retrieved June 9, 2011 from http://forum.ship-of-fools.com/cgi bin/ultimatebb.cgi?ubb=printopic;f=28;t=001297.

Neville, A., Balmer, N. J. \& William, A. M. (2002). The Influence of Crow Noise and Influence upon Referring Decision in Football. Psychology of Sport and Exercise, 3, 261-272.

Pollard, R. (1986). Home Advantage in Soccer: A Retrospective Analysis. Journal of Sports Sciences (JSS), 4, 237-24.

Qasim, I. (2006). Qasim terms Pak favorite. Retrieved June 12, 2011 from http://www.paktribune.com/sports/newsdetail.php?nid=599 